\title{
Analysing improvements to on-street public transport systems: a mesoscopic model approach
}

Ingvardson, Jesper Bláfoss; Kornerup Jensen, Jonas; Nielsen, Otto Anker

Published in:

Public Transport

Link to article, DOI:

10.1007/s12469-016-0151-x

Publication date:

2017

Document Version

Peer reviewed version

Link back to DTU Orbit

Citation (APA):

Ingvardson, J. B., Kornerup Jensen, J., \& Nielsen, O. A. (2017). Analysing improvements to on-street public transport systems: a mesoscopic model approach. Public Transport, 9(1-2), 385-409.

https://doi.org/10.1007/s12469-016-0151-x

\section{General rights}

Copyright and moral rights for the publications made accessible in the public portal are retained by the authors and/or other copyright owners and it is a condition of accessing publications that users recognise and abide by the legal requirements associated with these rights.

- Users may download and print one copy of any publication from the public portal for the purpose of private study or research.

- You may not further distribute the material or use it for any profit-making activity or commercial gain

- You may freely distribute the URL identifying the publication in the public portal 


\title{
Analysing improvements to on-street public transport systems: a mesoscopic model approach
}

\author{
Jesper Bláfoss Ingvardson · Jonas Kornerup Jensen · Otto Anker Nielsen
}

\begin{abstract}
Light rail transit and bus rapid transit have shown to be efficient and costeffective in improving public transport systems of cities around the world. As these systems comprise various elements, which can be tailored to any given setting, e.g. pre-board fare-collection, holding strategies and other Advanced Public Transport Systems (APTS), the attractiveness of such systems depend heavily on their implementation. In the early planning stage it is advantageous to deploy simple and transparent models to evaluate possible ways of implementation. For this purpose, the present study develops a mesoscopic model which makes it possible to evaluate public transport operations in details, including dwell times, intelligent traffic signal timings and holding strategies while modelling impacts from other traffic using statistical distributional data thereby ensuring simplicity in use and fast computational times. This makes it appropriate for analysing the impacts of improvements to public transport operations, individually or in combination, in early planning stages. The paper presents a joint measure of reliability for such evaluations based on passengers' perceived travel time by considering headway time regularity and running time variability, i.e. taking into account waiting time and in-vehicle time. The approach was applied on a case study by assessing the effects of implementing segregated infrastructure and APTS-elements, individually and in combination. The results showed that the reliability of on-street public transport operations mainly depends on APTS-elements, and especially holding strategies, whereas pure infrastructure improvements induced travel time reductions. The results further suggested that synergy effects can be obtained by planning on-street public transport coherently in terms of reduced travel times and increased reliability.
\end{abstract}

Keywords: BRT $\cdot$ LRT $\cdot$ APTS $\cdot$ Reliability analysis $\cdot$ Mesoscopic models $\cdot$ ITS 


\section{Introduction}

Bus Rapid Transit (BRT) and Light Rail Transit (LRT) are being implemented around the world due to the high attractiveness at a relatively low cost compared to underground systems (Hidalgo and Muñoz 2014). In Copenhagen the first BRT segment opened in 2014 and the first LRT line is scheduled to open in 2023. These systems comprise of segregated infrastructure, signal priority and other Intelligent Transport Systems (ITS) and Advanced Public Transport Systems (APTS) (Hwang et al. 2006). These elements may be implemented individually or in combination, locally or system-wide. The advantages of these systems include reduced travel times, improved comfort and increased reliability which is obtained through optimising the operations, for example by improved dwell time procedures, as compared to conventional bus services. Due to the varying implementation scopes and optimisation procedures, the potential effects will also differ greatly.

On-street public transport systems are complex due to (i) being affected by car traffic (unlike metro networks), and (ii) operations being very much dependent on the service characteristics, e.g. vehicle types, boarding and alighting procedures or holding controls. The effects of implementing BRT or LRT in favour of conventional bus services will vary significantly depending on the actual system design (Hensher and Golob 2008). Considering the complexity of mass public transport systems, which are large-scale, dynamic systems, combining multiple actors and require constant management and monitoring, such systems are inherently vulnerable (Cats, 2013; Kim et al. 2015; Reggianni et al., 2015). Because of the number of people served by the system, the importance of connectivity and accessibility in daily life and network propagation effects, any disruption can negatively impact the entire system resulting in high societal and economic costs (Cats 2013; Reggiani et al. 2015; Kim et al. 2015). For example, small disruptions to single vehicles have significant impacts in terms of congestion leading to crowding, discomfort and lower service reliability (Cats et al. 2016). In order to maintain a high level of reliability, transit operators operate within high inventory levels in terms of vehicle fleet and system buffer times. Because reliability is key for reducing inventory levels, reliability is increasingly sought in operation of critical infrastructure and high-reliability organizations in the transport sector, with the growing demand by stakeholders for lean operation (Pettersen and Schulman 2016).

The current study proposes new operational reliability indicators adoptable at the early planning stage. The study is motivated by the need to reduce the gap between the high importance of robustness analysis in transport planning, and the lack of a systematic evaluation of the consequences of service disruptions in network design processes and assessing the robustness value of new investments (Cats 2016). The proposed approach serves as a coping strategy with the inherently stochastic nature of transit systems due to daily fluctuations in traffic, travel demand and supply availability. For example, sources of travel time uncertainty are congestion in the network and dwell times which constitute up to $50 \%$ of the total travel time for buses in Copenhagen, each contributing with 20-25\% (Ingvardson and Jensen 2012a; Movia 2014). The contribution of the current study is three-fold.

Firstly, it provides new operational measures of reliability as perceived by passengers taking into account the stochasticity related to in-vehicle travel time and waiting time. Evaluating service reliability is important both from the supply side and the demand side perspective. In fact, a recent study from Copenhagen has shown that reliability is valued much higher than actual travel time (Prato et al. 2014).

Secondly, it complements Cats and Jenelius (2014) by applying a corridor-based mesoscopic model for reliability analysis. The proposed model stands in-line with other newly developed mesoscopic models, such as MATSim and BusMezzo. The model was originally developed as part of the thesis of the authors (Ingvardson and 
Jensen 2012a; Ingvardson and Jensen 2012b), but has been enhanced in several ways with the purpose of being able to model individual APTS elements as well as different on-street public transport systems. The model's simplicity, transparency and tractability make it suitable for evaluating reliability of on-street public transport systems in the early planning phases. Notably, the work of Cats and Jenelius (2014) focuses on system vulnerability due to irregularities in operations, while the current analysis focus on system reliability at the early planning stage by accounting for regular operational fluctuations in travel time variability and headway time regularity.

And thirdly, while the implementation of human-centric design and operational measures has been gaining momentum to improve system performance and level of service, a systematic evaluation of their impacts is scarce (Fadaei and Cats 2016). This study fills this knowledge gap by analysing and comparing the effects of individual operational building blocks, e.g. holding strategies and boarding procedures as well as their synergy effects in improving transit operations.

The remainder of this paper is structured as follows. Section 2 of the paper introduces the service reliability measure for evaluating the reliability of transport operations. The model approach is introduced in section 3, while section 4 presents the application on a case study corridor including model validation and definition of scenarios. Section 5 reports the results of the case study scenarios while section 6 discusses the applicability of the model and concludes the work.

\section{The proposed transit service reliability indicators}

Passengers' value of time in the public transport system differ significantly between spending time in the transport vehicles (in-vehicle time) and waiting and transferring between vehicles (out-of-vehicle time) (Nielsen 2000; Balcombe et al. 2004; Fosgerau et al. 2007). The inconvenience of waiting for the next transit vehicle, either at the departure stop or when transferring, makes it important to not only minimise travel times, but even more importantly minimise the waiting time for passengers (Parbo et al. 2014). Hence, when managing public transport it is crucial to ensure a reliable service. Ultimately unreliable operations make it necessary for the users to add a buffer to the travel time thus extending the actual travel time (Parbo et al. 2016).

Several definitions of reliability exist, also within public transport. A general formulation defines it as "continuity of correct service" (Avizienis et al. 2001). In a public transport context this can be interpreted as maintaining the same service as displayed in the public timetables. From the passengers' point of view this covers a combination of experiencing the anticipated waiting time at the stop, and experiencing the same in-vehicle travel time between stops. For high-frequency public transport operations this implies a low variation of running time while maintaining a homogeneous headway time between vehicles.

In this paper we propose a distribution-based service reliability measure suitable for high and medium-frequency public transport operations in a two-fold manner as sketched in Figure 1. It is reasonable to describe reliability in terms of distributions (Ceder 2007), hence measuring reliability in statistical terms. The mean, variation and coefficient of variation are therefore useful measures for the degree of variation of the operation. The lack of reliability can be quantified as the standard deviation multiplied by the corresponding value of time, hence supporting the use of statistical terms (Balcombe et al. 2004). Thus, the effective travel time includes the mean travel time and the standard deviation due to unreliability. This can be adopted for various time elements, e.g. running times, waiting times, etc. 


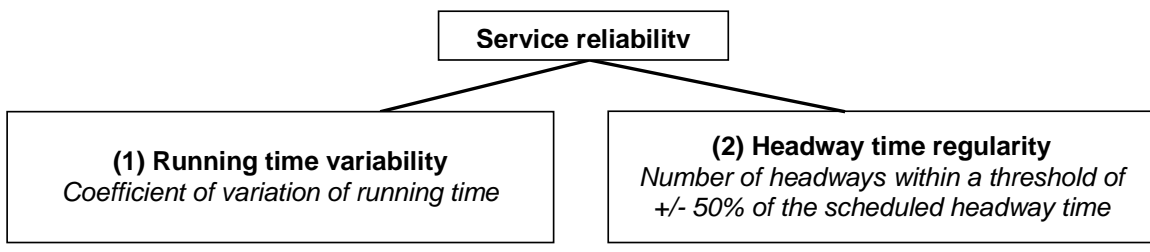

Figure 1: Measures of service reliability for high frequency public transport operations as proposed by Ingvardson and Jensen (2012a).

The metrics applied in the evaluation of service reliability in this study are: (1) the coefficient of variation of the running time (running time variability), and (2) the number of headway times within the threshold of $+/-50 \%$ of the scheduled headway time (headway time regularity). By using these measures it is possible to capture the service reliability of the public transport operations in terms of the total travel time experienced by passengers, i.e. the continuity of running times (in-vehicle times) and headway times (waiting times).

The proposed measures improve the indicators suggested by Nakanishi (1997) and Kittelson \& Associates et al. (2003), by extending them to better represent the actual service. Nakanishi (1997) propose an on-time performance indicator and a service regularity indicator. The on-time performance indicator is based on the percentage of trips departing from all scheduled time points, not including terminals, between 0 and 5 min after their scheduled departing time. The service regularity is measured as the percentage of headway times that deviates less than $50 \%$ from the scheduled headway. This measure also makes it possible to evaluate whether passengers experience a reliable service. Kittelson \& Associates et al. (2003) recommend headway adherence which is based on the coefficient of variation of the headway times at a given stop. The improvement in our proposed measures is three-fold.

Firstly, the new measures are based on running times instead of departures times in order to account for delay propagation in the system.

Secondly, we calculate the statistical distribution instead of a single value of headway time regularity, in order to account for operational stochasticity in daily service variation and to cope with the inherent uncertainty in the early planning stage.

And thirdly, instead of calculating aggregate measures at the zone-level or at every stop, the measures are calculated at important nodes in terms of size and system operation. This approach allows an efficient and transparent identification of connectivity cavities in the system.

\section{The proposed model}

Recent research efforts have resulted in several mesoscopic simulation models, e.g. BusMezzo (Cats 2011), MISTRANSIT (Cortés et al. 2007), SmartBRT (Werf 2005), MILATRAS (Wahba and Shalaby 2006), DYBUS/DYBUS2/DYBUSRT (Nuzzolo et al. 2001; Nuzzolo et al. 2015), and MATSim (Balmer et al. 2008). Focusing on transit operations, Toledo et al. (2010) evaluate the effects of varying passenger demand and travel time uncertainty on on-time performance and headway reliability of transit vehicles. Cats et al. (2012) and Fernandez et al. (2010) investigates the effects of various holding strategies on passengers in terms of headway variability, travel time and waiting times. Cats (2016) evaluate the effects of a network extension on crowding in transit vehicles. And Fernandez et al. (2010) evaluates the effects of station layouts and operational strategies in terms of passenger interchanges, bus operations at stops and stop capacity within busways. Other studies have analysed the applicability of mesoscopic models on large-scale test networks (Nuzzolo et al. 2016) and real networks (Wahba and Shalaby 2011; Neumann et al. 2012). 
This paper develops a mesoscopic simulation model in line with existing models for modelling public transit operations in a feedback loop with a macroscopic traffic assignment model. The mesoscopic model simulates the operation of public transit vehicles individually in a detailed manner whereas other traffic is macroscopically determined using the output of the macroscopic model, i.e. traffic volumes determining speed-density relationships, augmented with distributional data representing possible daily traffic fluctuations. The stochasticity of travel time is represented by sampling from link-specific distributions while traffic dynamics are explicitly modelled in the macroscopic model. The feedback loop allows for representing the implications of changes in running time on the number of passengers and traffic volumes, in order to plan for service robustness and reliability. Pedestrian and bicycle traffic at right/left turns in signalised intersections are represented in the current model by time penalties dependent on the signal timing plans of the traffic signals for cyclists and pedestrians.

The model is event-based where vehicles and their movements are simulated stepwise based on observations of bus behaviour in Copenhagen and Istanbul conducted as part of Ingvardson and Jensen (2012a) and Ingvardson and Jensen (2012b). This includes observations for different infrastructure designs, i.e. buses running in fully segregated busways, partly segregated bus lanes, and in mixed traffic at different congestion levels. Conventional bus operations are simulated by use of current observations from bus line $5 \mathrm{~A}$ in Copenhagen, whereas observations from the Metrobús system in Istanbul makes it possible to model infrastructure designs containing segregated busways. By utilising this form of data in the model it is possible to simulate the variation in operations without data on exact traffic levels in roads and intersections. An illustration of the overall work flow of the model is sketched in Figure 2.

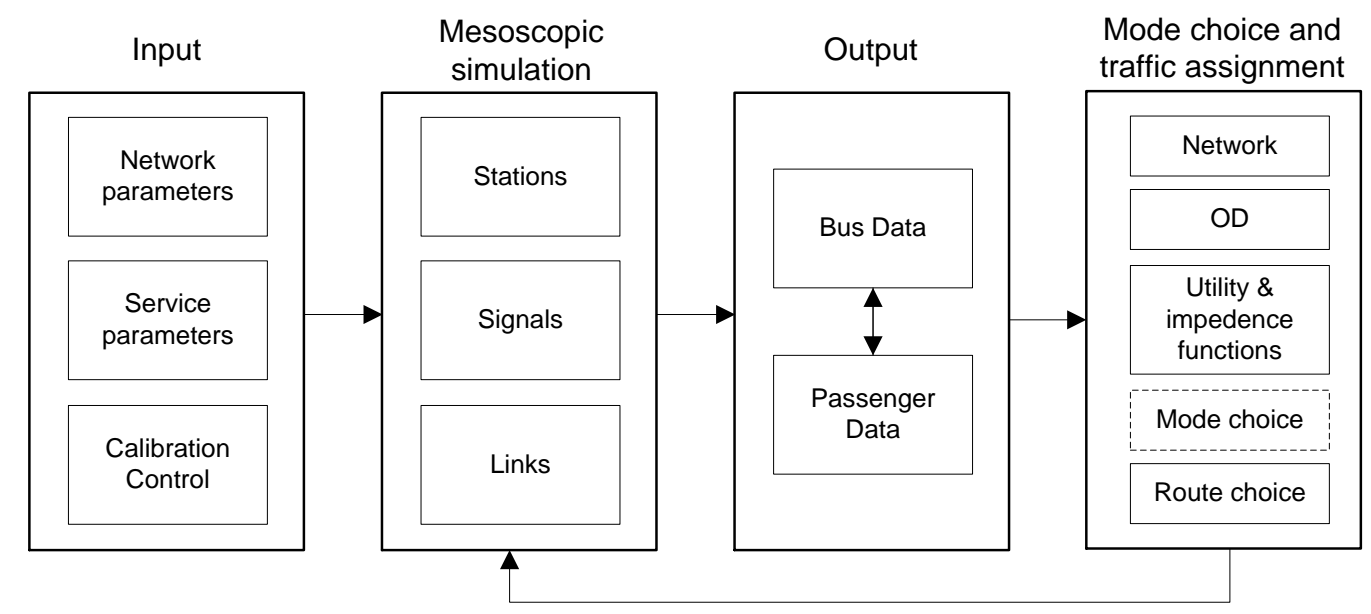

Figure 2: Illustration of the model framework including input, output, and the mode-choice and traffic assignment model feedback loop.

\subsection{Input}

The input to the model consists of characteristics related to the network, the passengers, and the operations of the public transport line. The input values are based 
on empirical data collected as part of Ingvardson and Jensen (2012a) and official data from public transport agency of Copenhagen (Movia). The data is implemented in a stochastic manner as statistical distributions. Hence, it is possible to simulate the variation of operations based on the statistical variation in the input parameters such as passengers boarding a specific vehicle.

\subsubsection{Network Parameters}

The network consists of links, signals, and stations. These are associated with a number of parameters, e.g. for links this includes the length and maximum speed whereas it for signals include the cycle time and green time.

\subsubsection{Service Parameters}

Service parameters are related to the level of service and the public transport operation. Hence, this includes the boarding and alighting time per passenger (depending on ticket type), and the vehicle seat capacity for evaluating comfort levels. The dispatching input includes the headway time between departures at the starting node and the level of randomness by which buses are dispatched, i.e. the level of bunching at the departure stop.

\subsubsection{Calibration Controls}

To capture minor variations of the operations a number of calibration control parameters have been implemented. These parameters include holding controls, and reflect the behaviour of a driver who catches up with a bus and thus holds back to ensure a certain time gap between the vehicles. These parameters are also used when simulating different bunching controls.

\subsection{Simulation}

The simulation of vehicles is based on the characteristics of the operations which suggest that the travel time of an individual vehicle basically consists of three elements: (i) time spent to overcome distance, (ii) time spent dwelling at stops, and (iii) potentially time spent waiting at traffic signals. The time spent on links overcoming distance depends on the speed and acceleration profile of the vehicle and external factors such as congestion if driving in mixed traffic. Time spent at stops depends on a fixed amount of time for deceleration and acceleration and for opening and closing the doors. Additionally there is a variable amount of time used for passengers to board and alight the vehicle which is dependent on vehicle and service planning characteristics. The same is the case for signals along the route where the vehicle potentially uses a fixed amount of time to decelerate and accelerate and a variable amount of time for waiting at the signal. At each event for every vehicle the model will calculate the position, time and occupancy, e.g. when arriving at a stop these parameters are calculated based on the input variables, cf. Figure 3. 


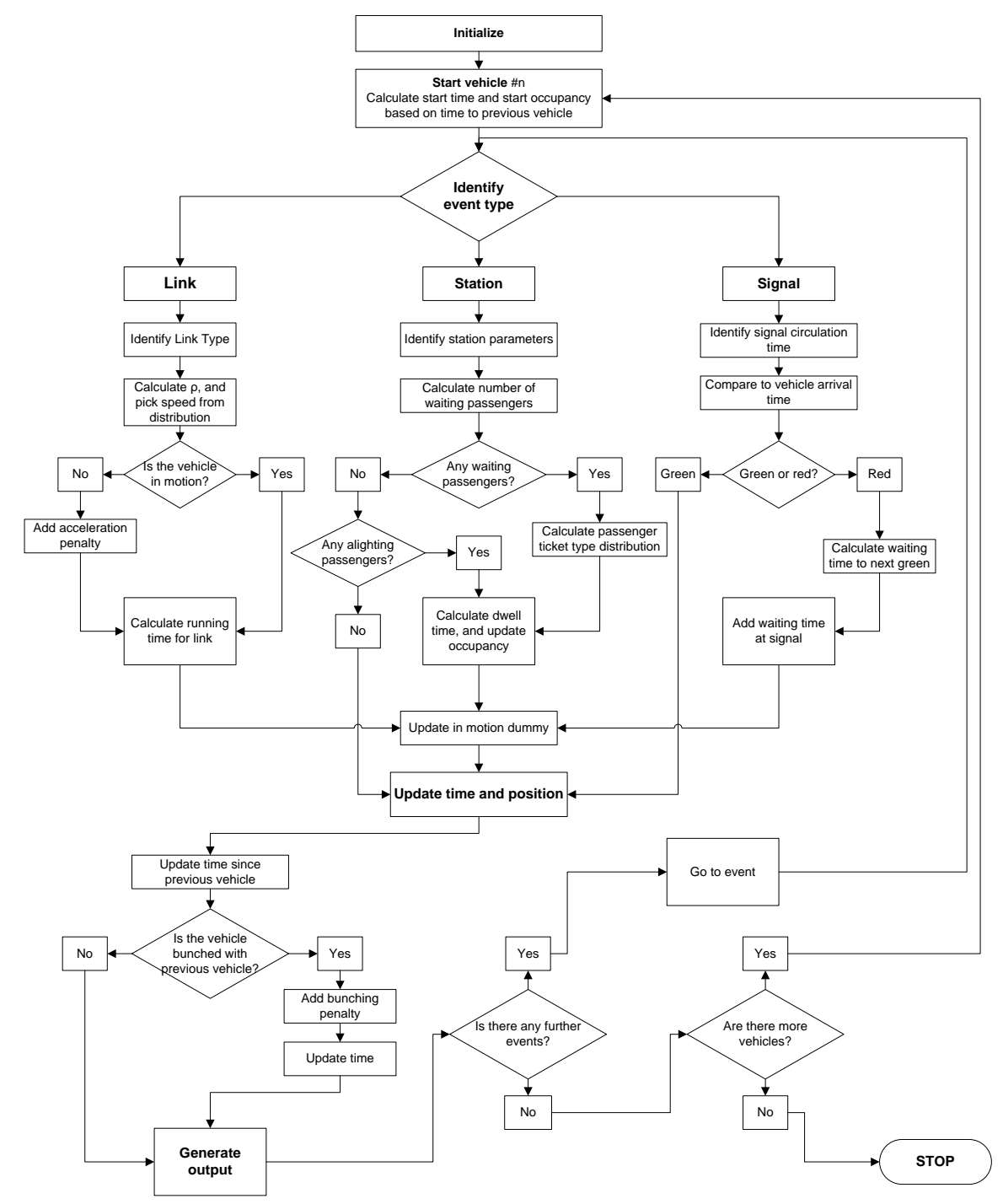

Figure 3: Detailed overview of the model simulation framework. More information can be found in Ingvardson and Jensen (2012a).

After initialising the model with relevant input the first vehicle is assigned. The bus initially identifies the first event. Then the time, distance travelled, and changes in occupancy at the event are calculated. The output from the event is an update of this information (time, location, and occupancy) which is used as input to the next event. At every event the headway times between vehicles are calculated as this is used to calculate the number of passengers waiting at stops and to control bunching and possible overtakings if such are allowed. Also, a dummy variable denoting whether the vehicle is in motion or not is updated. This dummy is implemented as the travel time on a link is dependent on whether the vehicle is already in motion or if it needs to accelerate. When all vehicles have been through all events, i.e. travelled the entire corridor, it is possible to calculate and evaluate the effects for vehicles and passengers. If a scenario results in significant travel time reductions the output will be used as input to an assignment model making it possible to evaluate the changes to passengers' route choices. This is important in order to evaluate the effects for passengers on the public transport line being investigated as well as in the entire public transport network. 


\subsubsection{Links}

The time spent travelling on links generally depends on trip time (e.g. hour, day, week, season), number of passengers, and the habits of the individual driver (Ceder 2007). In traditional traffic assignment models the travel time on links can be estimated according to traffic flow theory (Ortúzar and Willumsen 2011). As this mesoscopic simulation model does not model car traffic this approach is not adopted. Instead this model estimates the speed of the public transport vehicle on a given link based on empiric speed data.

The framework for calculating the speed of public transport vehicles is based on letting the speed be randomly distributed thus simulating that the travel speed both depend on local conditions of the road and on external factors such as the driving behaviour. Hence, when a given vehicle arrives at a given link the speed on that link will be randomly drawn from an appropriate link-specific distribution. In this way it is possible for the model to calculate the time it takes for the vehicle to travel on that link. To include the fact that the characteristics of the road influence the speed of the vehicle the links in the network has been categorised into different link types, see Table 1.

\begin{tabular}{clr} 
Link Type & \multicolumn{1}{c}{ Description } & Congestion level \\
\hline W & $\begin{array}{l}\text { No disturbance from other traffic. This includes } \\
\text { busways only. } \\
\text { Low disturbance from other traffic. This }\end{array}$ \\
N $\quad \begin{array}{l}\text { includes bus lanes only. } \\
\text { Medium disturbance from other traffic. This } \\
\text { includes mixed use lanes. }\end{array}$ & - \\
K $\quad \begin{array}{l}\text { High disturbance from other traffic. This } \\
\text { includes road with some congestion. }\end{array}$ & $0.80-1.00$ \\
H $\quad \begin{array}{l}\text { Very high disturbance from other traffic. This } \\
\text { includes roads with major congestion. }\end{array}$ & $0.00-0.55$ \\
\hline Table 1: $\quad$ List of link types used in the model.
\end{tabular}

The categorisation of link types is based on the travel speed, the availability of bus lanes or busways, and the traffic congestion level defined by the actual speed, $v$, and the free speed of the link, $v_{f}$, as $\left(1-v / v_{f}\right)$. Both measures are included to take into account the variability of travel speed as this to a large extent depends on the congestion level. The actual travel speeds are based on GPS data for a number of cars traveling in the Copenhagen area during 2014. In other contexts where GPS data is not available the actual speeds can also be based on output from the traffic assignment model.

Each link type has been assigned a number of parameters which makes it possible to calculate the travel time for the transit vehicle on a given link. These parameters include the mean and standard deviation of the top speed on the link in addition to a penalty term which takes into account the acceleration of the vehicle for reaching that specific maximum speed. The latter is only included if the vehicle has been brought to a stop at the previous event such as at a red signal.

The distributional data of travel speeds of the public transport vehicle for the five different link types are based on empirical data collected as part of Ingvardson and Jensen (2012a). This data was tested using the Shapiro-Wilk test (Shapiro and Wilk 1965 ) in order to justify the assumption of the data being random and normally distributed. This test was chosen due to its higher statistical power than the Kolmogorov-Smirnov, Lilliefors and Anderson-Darling tests (Razali and Wah 2011). 


\begin{tabular}{ccrrrr}
$\begin{array}{c}\text { Link } \\
\text { Type }\end{array}$ & Distribution & $\begin{array}{c}\text { Mean } \\
{[\mathbf{k m} / \mathbf{h}]}\end{array}$ & $\begin{array}{c}\text { Standard } \\
\text { Deviation } \\
{[\mathbf{k m} / \mathbf{h}]}\end{array}$ & W & Pr < W \\
\hline W & Normal & 60.5 & 4.85 & 0.933 & 0.2225 \\
N & Normal & 37.4 & 3.60 & 0.943 & 0.1562 \\
M & Normal & 26.0 & 3.18 & 0.977 & 0.3840 \\
K & Normal & 17.9 & 2.96 & 0.965 & 0.3089 \\
H & Normal $^{1}$ & 9.8 & 3.06 & 0.945 & 0.4527 \\
\hline
\end{tabular}

Table 2: Test for normality for the empiric data of travel speeds for the five link types.

The test results presented in Table 2 show that the assumption cannot be rejected at a $95 \%$ confidence level. Thus, the normal distribution is accepted as providing a good fit for the data. Due to the nature of the normal distribution which is symmetric around the mean it has been necessary to limit the possible values for links of type $\mathrm{H}$. The speed on these links can only take on values between 5 and $15 \mathrm{~km} / \mathrm{h}$. This has been done to avoid very low or even negative speeds in the model.

As the speed of each vehicle is drawn randomly vehicles that are traveling close together can travel at quite different speeds. As this is not realistic dependency between speeds of successive vehicles has been implemented. This dependency is implemented by letting the speed of a given vehicle be partly dependent on the speed of the previous vehicle. Both vehicles will have a speed drawn from the appropriate distribution from the given link type. However, if two vehicles travel within 15 seconds of each other on the same link the second vehicle will adopt the same speed as the first vehicle. If the headway time between successive vehicles on a specific link is more than 180 seconds the travel speeds will be fully independent. The transition between full dependency and full independency of travel speeds is calculated linearly as $(180-t) / 165$, where $t$ is the time between vehicles. This is illustrated by an example: Two transit vehicles travelling on the same link (link type M) at a headway time of 60 seconds results in 0.73 . The vehicles draw speeds from the appropriate distribution, cf. Table 2, resulting in speeds of say $28.79 \mathrm{~km} / \mathrm{h}$ for the first vehicle and $22.47 \mathrm{~km} / \mathrm{h}$ for the second vehicle. In the model the first vehicle will then be assigned the speed of $28.79 \mathrm{~km} / \mathrm{h}$ (assuming that no other vehicles travelled this link within 180 seconds prior to the first vehicle). The second vehicle will due to the short headway time not travel at $22.47 \mathrm{~km} / \mathrm{h}$. Instead the speed is adjusted to $0.73 * 28.79+(1-0.73) * 22.47=27.07 \mathrm{~km} / \mathrm{h}$. By this the model ensures that vehicles travelling at very short headways, i.e. in very similar traffic conditions, do not travel at very different speeds.

\subsubsection{Signals}

Signals are modelled as nodes and are based on the signal timing plans using three input parameters: (i) the cycle time, (ii) the start time for the green phase, and (iii) the end time for the green phase. The model then calculates the potential waiting time until the next green for a given vehicle approaching a given signal. Signals that have priority for public transport vehicles are modelled using extended green times. For traditional bus operations there is no full transit priority in signals, i.e. buses have to yield for pedestrians and bicycles when turning right, and also for car traffic when turning left. Such delays caused by other traffic have been implemented by use of time penalty. By this the model can be used to evaluate signal prioritisation measures for the public transport vehicles.

\footnotetext{
${ }^{1}$ Can only take on values in the interval $[5,15]$
} 


\subsubsection{Stations}

Stations are modelled as nodes with two parallel procedures being calculated simultaneously; (i) the number of boarding passengers, and (ii) the number of alighting passengers. These are used to calculate the total dwell time for the bus.

The dwell time calculations depend on the type of boarding process. When all passengers board and alight through the same door the dwell time can be estimated by a linear model of the form (Ceder 2007):

$$
D_{i k}=\left\{\begin{array}{cl}
b+\delta_{B} \cdot B_{i k}+\delta_{A} \cdot A_{i k} & \text {, if } B_{i k}>0 \text { or } A_{i k}>0 \\
0 & \text {, if } B_{i k}=A_{i k}=0
\end{array}\right.
$$

For vehicles with multiple doors where boarding and alighting passengers use different doors the dwell time can be calculated as (Ceder 2007):

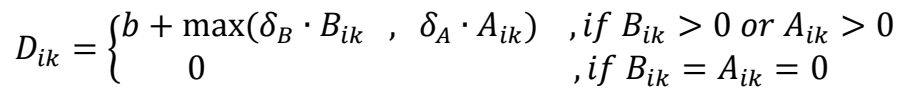

where $D_{i k}$ is the dwell time of the vehicle serving trip $i$ at stop $k$ including the time required for acceleration and deceleration ( $\mathrm{D}_{\mathrm{ik}}=0$ if vehicle $i$ do not stop at stop $k$ ); $b$ is the dead time portion including acceleration, deceleration, and closing and opening of doors; $B_{i k}$ is the number of passenger boarding the vehicle serving trip $i$ at stop $k ; A_{i k}$ is the number of passenger alighting the vehicle serving trip $i$ at stop $k ; \delta_{B}$ is the marginal dwell time per boarding passenger; $\delta_{A}$ is the marginal dwell time per alighting passenger.

This model suggests that the total dwell time for a vehicle can be estimated by a fixed time including acceleration and deceleration, and opening and closing of doors, and a variable time depending on the number of passengers boarding and alighting the vehicle. If the vehicle has separate doors for boarding and alighting passengers these events happen independently of each other, and the variable term of the dwell time then depends on the event which takes the longest time. However, if the vehicle has only one door, or the doors are used for both boarding and alighting, the events cannot happen simultaneously. For BRT and LRT the latter will to some extent be the case as the doors are used by both boarding and alighting passengers hence creating conflicts.

The number of boarding passengers at a stop, i.e. passengers arriving at a stop, is assumed to be random as the frequency is high with headway times of less than 5 minutes (Nakanishi 1997). At such low headway times the proportion of passengers arriving in coordinated arrival patterns is rather low (Neumann et al. 2013). Hence, the arrival intensity is assumed to follow the Poisson distribution similar to in Cats et al. (2010). From this it follows that the time between passenger arrivals, the passenger headway time, is exponentially distributed. Hence, the number of boarding passengers at a given departure at a given stop can be calculated based on the mean passenger arrival intensity for that given stop.

The number of alighting passengers at a given stop is assumed to follow the binomial distribution (Andersson and Scalia-Tomba 1981; Liu and Wirasinghe 2001; Toledo et al. 2010). Hence, it is calculated based on the occupancy of a given vehicle at a given stop and the share of passengers alighting at that stop in the given time period.

\subsection{Output}


The output of the model consists of the time, position, and occupancy for all modelled vehicles at all events. This is then used to evaluate level of service parameters such as waiting times at stops, travel time for vehicles and passengers, and headway time distributions. By this it is possible to evaluate the operations including the experienced service reliability as experienced by passengers, and to compare the effects obtained by implementing various technologies including APTS elements individually as well as full BRT or LRT scenarios.

\subsection{Mode choice and traffic assignment model}

The model framework includes a feedback algorithm between the mesoscopic simulation model and a combined mode choice and traffic assignment model. The feedback algorithm allows for modelling changes to passenger flows in the public transport network resulting from improvements to the service operations on a single public transport line as modelled by the mesoscopic simulation model. The output from the mesoscopic model in terms of dwell times and running times between stops are used as input to the traffic assignment model which estimates the impacts of the updated travel times on mode choice and passengers' route choice in the public transport network. The output in terms of a new OD-matrix for passengers on the public transport line is then used as input to the next iteration of the mesoscopic simulation model. The feedback continues until steady-state conditions are attained. In this model framework such conditions are attained when the total running time for the public transport line changes by less than 1 minute. This threshold was chosen because the input of running times to the traffic assignment model is given in whole minutes.

The feedback loop requires car and public transport networks as well as origindestination matrices as input. Mode choices and route choices are estimated based on random utility theory using utility functions and impedance functions taking into account volume-delay relationships. The traffic assignment model makes it possible to describe passengers' different preferences towards public transport modes and transfers in a schedule-based configuration (Nielsen 2004) within a reasonable calculation time (Nielsen and Frederiksen 2006).

The feedback algorithm is optional, and the mode choice and route choice models can be run individually.

\section{Case Study Corridor}

The selected case study corridor is part of the busiest bus line in the Copenhagen area, 5A, which runs between Husum Torv and Sundbyvester Plads, cf. Figure 4. The bus line is part of the high-frequency A-bus network covering the dense areas of Copenhagen with short distances of 3-400 meters between stops. The bus line 5A links the city centre with two of the most dense city districts, namely Amagerbro in the southern part and Nørrebro in the north-eastern part of Copenhagen. The passengers on this line travel an average of $2.60 \mathrm{~km}$ which is shorter than on other bus lines, partly due to using the bus as feeder to metro or suburban railway lines. Hence, only $16 \%$ of passengers on line $5 \mathrm{~A}$ travel across both corridors. The paper analyse the southern section between Nørreport station and Sundbyvester Plads. This segment is $6.5 \mathrm{~km}$ long and currently covers 18 stops. 


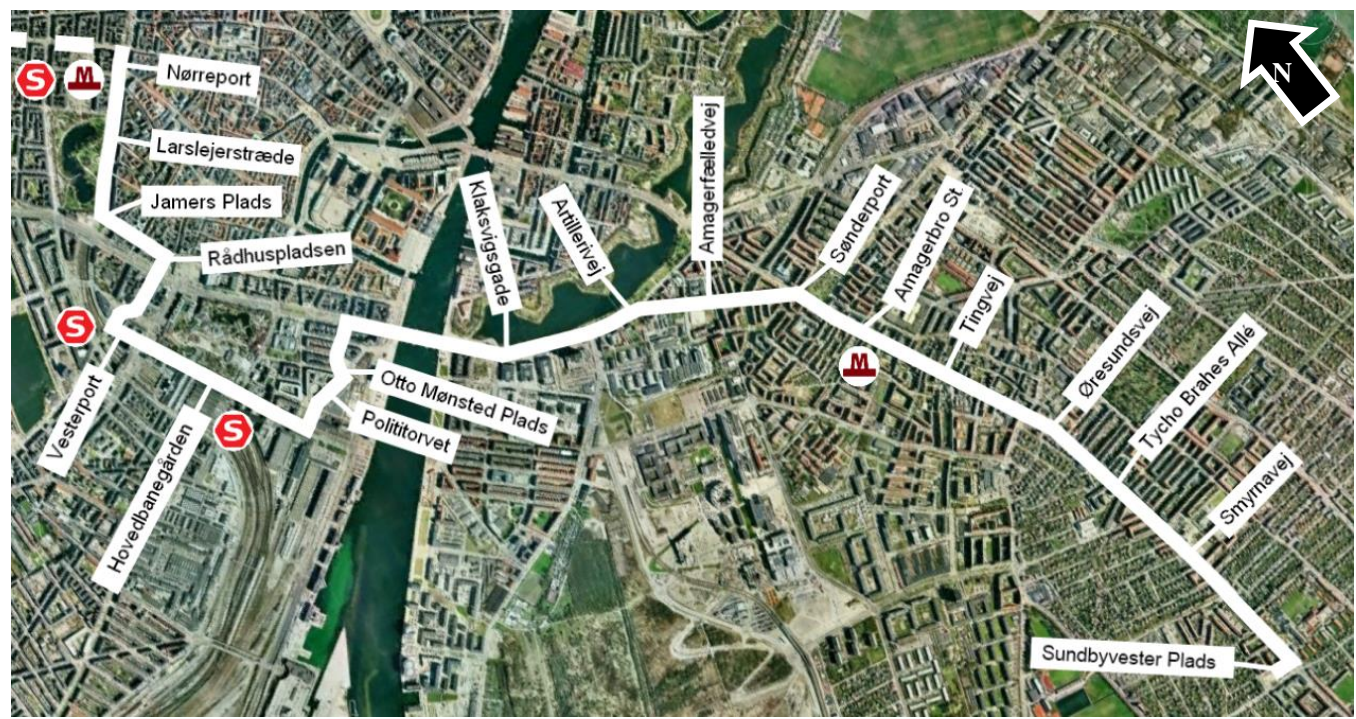

Figure 4: The 5A corridor between Nørreport station in central Copenhagen and Sundbyvester Plads on Amager.

Currently, approximately $40 \%$ of the corridor has dedicated bus lanes and several APTS elements are already implemented including bus priority in selected traffic signals and real-time traffic information for passengers based on automatic vehicle location (AVL). Despite these elements the operation suffers from low reliability and slow travel speeds (Ingvardson and Jensen 2012a).

\subsection{Data}

The base scenario was based on manually collected data as well as AVL bus data for the current bus operations of 5A in Copenhagen. Manually collected data was used for bus speeds and headway time distributions at Amagerbro station and Nørreport station (Ingvardson and Jensen 2012a) because the AVL data available did not include distributional data. AVL aggregate data for the autumn of 2014 was used for passenger numbers and to validate the model.

\subsection{Model Replication}

The model was run for a typical morning peak period, 7am-9am, including 72 buses (18 per hour per direction). The input parameters were altered randomly to introduce noise, and the results are averages of 50 runs.

The validation of whether the simulated model results accurately replicate the real world has been done by two-sample Kolmogorov-Smirnov tests, similar to in Cats et al. (2010). Statistical distributional data of the actual operations were only available for Amagerbro station in both directions and at Nørreport station in the northbound direction. Hence, the parameter that is being tested is the distributions of headway times at these locations. The test results shown in Table 3 imply that the model replicates real-world operations sufficiently well. 


\begin{tabular}{lccc}
\multicolumn{1}{c}{ Test parameters } & D & KSa & Pr > KSa \\
\hline $\begin{array}{l}\text { Amagerbro st. } \\
\text { Southbound } \\
\text { Amagerbro st. }\end{array}$ & 0.1313 & 0.9033 & 0.3882 \\
$\begin{array}{l}\text { Northbound } \\
\text { Nørreport st. }\end{array}$ & 0.1214 & 0.8565 & 0.4555 \\
Northbound & & & \\
\hline
\end{tabular}

Table 3: Kolmogorov-Smirnov tests for validating the model replication of the headway distributions.

Optimally this validation method should be used for all relevant parameters in the validation process. However, the observed data on running times and time use shares did only include mean values from the buses and not distributional data. Hence, it was not possible to validate the model in this manner with regards to running time and time use shares. Instead the validation of these parameters was done by use of mean and standard deviation values, cf. Table 4.

\begin{tabular}{lcccc} 
Northbound & $\begin{array}{c}\text { Average running } \\
\text { time }\end{array}$ & $\begin{array}{c}\text { Running time } \\
\text { variability }\end{array}$ & $\begin{array}{c}\text { Commercial } \\
\text { speed [km/h] }\end{array}$ & $\begin{array}{c}\text { Headway time } \\
\text { regularity }\end{array}$ \\
\hline Observed base & $27 \mathrm{~min} 29 \mathrm{sec}$ & $9.2 \%$ & 14.2 & $54 \%$ \\
Modelled base & $27 \mathrm{~min} 25 \mathrm{sec}$ & $6.3 \%$ & 14.2 & $56 \%$ \\
\hline & Average running & Running time & Commercial & Headway time \\
Southbound & time & variability & speed [km/h] & regularity $^{3}$ \\
\hline Observed base & 23 min $59 \mathrm{sec}$ & $6.2 \%$ & 16.3 & $47 \%$ \\
Modelled base & 23 min 50 sec & $6.0 \%$ & 16.4 & $58 \%$ \\
\hline
\end{tabular}

Table 4: Model simulation results for the base situation compared to the real base situation.

The comparison shows that the model replicates reality well with regards to travel time. However, the modelled service reliability measures differ from the observed values, i.e. lower running time variability and higher headway time regularity. Hence, it seems that the model has difficulties simulating large reliability problems. One of the reasons for this might be the models lack of ability to model larger breakdowns in the network, e.g. traffic jams, or taxis or trucks blocking bus lanes. A detailed overview of the running time adherence of the modelled base situation is shown in Table 5.

\footnotetext{
${ }^{2}$ Headway time regularity as average of Amagerbro station and Nørreport station.

3 Headway time regularity at Amagerbro station only.
} 
Southbound

Northbound

\begin{tabular}{lcrrrrrrr} 
Stop & Km & Observed & Model & Difference & Km & Observed & Model & Difference \\
\hline Nørreport st & 0,000 & 0 & 0 & 0 & 6,517 & 1649 & 1645 & -4 \\
Larslejsstræde & 0,408 & 96 & 109 & 13 & 6,109 & 1540 & 1553 & 13 \\
Jarmers Plads & 0,722 & 173 & 184 & 11 & 5,795 & 1505 & 1521 & 16 \\
Rådhuspladsen & 0,943 & 220 & 244 & 24 & 5,574 & 1386 & 1395 & 9 \\
Vesterport st & 1,215 & 298 & 319 & 21 & 5,302 & 1297 & 1311 & 14 \\
Hovedbanegården & 1,695 & 466 & 459 & -7 & 4,822 & 1111 & 1131 & 20 \\
Polititorvet & 2,116 & 624 & 622 & -2 & 4,401 & 958 & 970 & 12 \\
Otto Mønsteds Plads & 2,366 & 667 & 667 & 0 & 4,151 & 905 & 901 & -4 \\
Klaksvigsgade & 3,127 & 796 & 805 & 9 & 3,390 & 761 & 757 & -4 \\
Ørestad Boulevard & 3,486 & 890 & 877 & -13 & 3,031 & 696 & 690 & -6 \\
Amager Fælledvej & 3,972 & 966 & 967 & 1 & 2,545 & 600 & 587 & -13 \\
Sønderport & 4,214 & 1005 & 1004 & -1 & 2,303 & 549 & 536 & -13 \\
Amagerbro st & 4,580 & 1083 & 1073 & -10 & 1,937 & 430 & 429 & -1 \\
Tingvej & 4,930 & 1160 & 1154 & -6 & 1,587 & 323 & 338 & 15 \\
Øresundsvej & 5,118 & 1196 & 1186 & -10 & 1,399 & 234 & 238 & 4 \\
Tycho Brahes Alle & 5,627 & 1272 & 1267 & -5 & 0,890 & 158 & 157 & 76 \\
Smyrnavej & 6,070 & 1347 & 1349 & 2 & 0,447 & 74 & 0 & -1 \\
Sundbyvester Plads & 6,517 & 1439 & 1430 & -9 & 0,000 & & 2 \\
\hline Tab 5: Run & & & & & 0 \\
\hline
\end{tabular}

Table 5: Running time adherence of the model results compared to base situation

The model estimates of the travel time between stops reflect the observed values in an acceptable manner, i.e. the variation between the observed and model estimates of accumulated times at stops are less than 30 seconds for all stops.

\subsection{Scenarios}

The model was applied to analyse the effects of different APTS upgrades of the current 5A bus line in Copenhagen. Furthermore, the effects of implementing full BRT and LRT systems involving multiple APTS elements were analysed. The scenarios are outlined in Table 6.

\section{Scenarios}

\begin{tabular}{|c|c|c|c|c|}
\hline \multirow{2}{*}{$\begin{array}{l}\text { Infrastructure only } \\
\text { Planning and technology only }\end{array}$} & \multicolumn{4}{|c|}{ Fully segregated busways and additional bus lanes } \\
\hline & $\begin{array}{l}\text { Pre-board fare } \\
\text { collection }\end{array}$ & $\begin{array}{l}\text { Specialised vehicles } \\
\text { with multiple doors }\end{array}$ & Bunching controls & $\begin{array}{l}\text { All planning and } \\
\text { technology elements. }\end{array}$ \\
\hline Full system solutions & \multicolumn{2}{|c|}{$\begin{array}{l}\text { Full BRT system including a combination of } \\
\text { segregated infrastructure, and planning and } \\
\text { technology elements. }\end{array}$} & \multicolumn{2}{|c|}{$\begin{array}{l}\text { Full LRT system including a combination of } \\
\text { segregated infrastructure, and planning and } \\
\text { technology elements. }\end{array}$} \\
\hline
\end{tabular}

Table 6: Overview of the performed analyses of upgrades to the current bus operations.

\subsubsection{Infrastructure scenarios}

The infrastructure only scenario applied segregated busways on segments where possible while ensuring that existing traffic was not influenced significantly. The corridor was hence upgraded with a total of $2.8 \mathrm{~km}$ busways fully segregated from car traffic along the $6.5 \mathrm{~km}$ corridor. On these segments the transit vehicles ran in the middle of the road physically separated from car traffic in order to ensure the fastest 
possible operation. In addition, $1.2 \mathrm{~km}$ had dedicated lanes for the public transport vehicles. An overview of the upgraded infrastructure is shown in Figure 5.

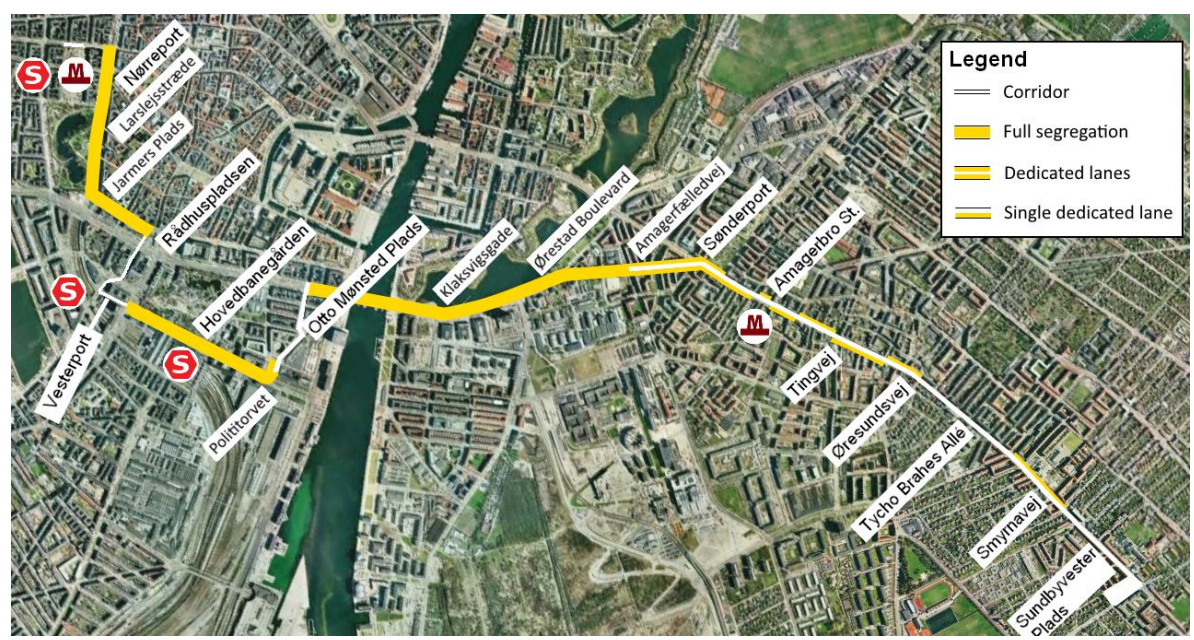

Figure 5: The layout of the proposed infrastructure upgrades of the 5A corridor between Nørreport station and Sundbyvester Plads.

\subsubsection{Planning and technology scenarios}

The planning and technology scenario only included upgrades to the vehicle fleet and the operation of vehicles. Pre-board fare collection was implemented, and vehicles with different door configurations were tested. Adding additional doors will allow for a faster exchange of boarding and alighting passengers, and automatic fare collection allows for faster and more homogeneous passenger boarding times. Also, dynamic holding was analysed in order to prevent bunching of vehicles. Finding the optimal holding strategy has been the focus of many studies, see a review of strategies in Strathman et al. (2001). Cats et al. (2012) test different holding strategies in terms of holding criteria and time point and find that headway-based strategies are superior to schedule-based strategies. Reliability is further improved by adapting holding to both the preceding and following bus. Other studies have seen improved results by proposing adaptive control schemes that holds back or slow buses continuously based on real-time information of headways rather than on specific stops (Daganzo and Pilachowski 2011; Xuan et al. 2011). Two holding strategies were adopted;

The first strategy was based on continuously holding back vehicles if the headway time becomes smaller than a defined threshold. As the reliability measure is defined based on headway times in the interval $+/-50 \%$ of the scheduled headway time, the same threshold was applied for the holding strategy. Hence, a vehicle was told to slow down if the headway time to the vehicle in front was less than $50 \%$ of the scheduled headway time. Similarly, vehicles running ahead of a delayed vehicle were slowed down to ensure even headways between vehicles. Nagel and Neumann (2010) show that such a strategy helps to reduce the average delay of the vehicle, the passengers' travel time and bus bunching caused by minor delays. In the model this was achieved by adding two seconds to the running time at links and dwell time at stops if the headway time was less than $50 \%$ of scheduled or more than $150 \%$, respectively.

The second holding strategy was simpler as vehicles were only held back at stops. The same thresholds were applied, but the vehicles were held back for five seconds.

A BRT Lite scenario incorporating pre-board fare collection, vehicles with four double doors, and the dynamic holding strategy that slows down vehicles at stops and links was also analysed.

The scenarios involving different public transport vehicles incorporate different dwell time parameters as listed in Table 7. 


\begin{tabular}{|c|c|c|c|c|}
\hline $\begin{array}{l}\text { Number of } \\
\text { double doors } \\
\text { for boarding }\end{array}$ & $\begin{array}{c}\text { Boarding time } \\
\text { per passenger } \\
\text { [sec] }\end{array}$ & $\begin{array}{c}\text { Alighting time } \\
\text { per passenger } \\
\text { [sec] }\end{array}$ & $\begin{array}{l}\text { Dead time } \\
\text { [sec] }\end{array}$ & Source \\
\hline 1 & $1.45 / 1.82 / 10.55^{4}$ & 0.50 & 10.95 & (Ingvardson and Jensen 2012a) \\
\hline 1 & 1.53 & 0.39 & $8.70^{5}$ & (Ingvardson and Jensen 2012a) \\
\hline 2 & 0.70 & 0.60 & $8.00(+3.52)^{6}$ & $\begin{array}{r}\text { (Ingvardson and Jensen 2012a), } \\
\text { (Highway Capacity Manual 2000) }\end{array}$ \\
\hline 3 & 0.50 & 0.40 & $8.00(+3.52)^{6}$ & $\begin{array}{r}\text { (Ingvardson and Jensen 2012a), } \\
\text { (Highway Capacity Manual 2000) }\end{array}$ \\
\hline 4 & 0.25 & 0.46 & $8.00(+3.52)^{6}$ & (Ingvardson and Jensen 2012a) \\
\hline
\end{tabular}

Table 7: Dwell time parameters used in the analyses.

The parameters used for the analyses were collected from buses in Copenhagen and Istanbul (Ingvardson and Jensen 2012a). Pre-board fare collection was not implemented in the base scenario; hence passenger boarding times depend on the ticket type used ranging between 1.45 seconds for a pre-paid ticket, 1.82 seconds for so-called stamp cards ${ }^{7}$, and 10.55 seconds if buying a cash ticket at the driver. In the base situation $62 \%$ of passengers use pre-paid tickets, $32 \%$ use stamp cards, and $6 \%$ buy cash tickets according to the public transport agency in Copenhagen. When implementing pre-board fare collection while only boarding through the front door the boarding time per passenger is reduced only marginally. This is due to the narrow layout of the buses which require passengers to board in one single line. Vehicles that allow for boarding and alighting through more doors reduce the boarding times notably as multiple passengers can board simultaneously without being hindered by potential jams at the front door (Neumann et al. 2014).

The boarding and alighting times were based on the Highway Capacity Manual (Highway Capacity Manual 2000) and Ingvardson and Jensen (2012a).

\subsubsection{Full system scenarios}

The individual upgrades were combined into two different system scenarios, BRT and LRT. These scenarios included the same upgrades to infrastructure ensuring segregation from car traffic where possible. Both scenarios incorporated the same improvements to the boarding and alighting process including pre-board farecollection, traffic signal priority and bunching controls. Hence, the systems were meant to replicate systems such as the Malmö Express BRT and Bergen Bybanen LRT.

Due to unavailability of statistical distributional data for LRT the calculation of running time on links was performed differently than specified in section 3.2.1. Running times for the light rail vehicles were then calculated based on vehicle characteristics. Hence, travel times on links were calculated based on the maximum allowed speed on the links. In fully segregated busways and bus lanes this was set to $60 \mathrm{~km} / \mathrm{h}$. In mixed traffic it was set to $40 \mathrm{~km} / \mathrm{h}$ or $50 \mathrm{~km} / \mathrm{h}$ depending on the link type.

\footnotetext{
${ }_{4}^{4}$ Boarding times in base situation with on-board fare collection using different ticket types $(62 \%$ prepaid, $32 \%$ stamp card, and 6\% cash-ticket). More information can be found in (Ingvardson and Jensen 2012a).

5 Boarding and alighting from different independent doors. Adapted from (Ingvardson and Jensen 2012a).

${ }^{6}$ Boarding and alighting from multiple doors with a congestion penalty of 3.52 seconds if the bus is near capacity limit. Adapted from (Ingvardson and Jensen 2012a).

${ }^{7}$ Stamp cards are 10-fare cards that need to be stamped in a machine when entering the vehicle.
} 
The actual average speeds on links are lower because the model takes into account potential acceleration and deceleration prior to and after the link. Also, the top speed can only be reached by the vehicle if travelling for a sufficiently long distance. In addition a running time supplement was added to links ranging from 5-20\% depending on the congestion levels. The simulation of dwell times was performed using characteristics for a bus with four double doors. Hence, the modelling of the two scenarios was identical, except for the speed calculations.

\section{Results}

The main results of the various scenarios with regards to travel time and reliability are summarised in Table 8 for the morning peak period (7-9). All scenarios required one single iteration of the feedback loop, i.e. one assignment model and two runs of the mesoscopic model per scenario.

\begin{tabular}{|c|c|c|c|c|c|c|c|}
\hline Scenario & $\begin{array}{l}\text { Avg. running } \\
\text { time }\end{array}$ & $\begin{array}{l}\text { Commercial } \\
\text { speed }[\mathrm{km} / \mathrm{h}]\end{array}$ & $\begin{array}{c}\text { Change } \\
\text { [\%] }\end{array}$ & $\begin{array}{l}\text { Running time } \\
\text { variability }\end{array}$ & $\begin{array}{c}\text { Change } \\
\text { [\%] }\end{array}$ & $\begin{array}{l}\text { Headway time } \\
\text { regularity }^{8}\end{array}$ & $\begin{array}{c}\text { Change } \\
\text { [\%] }\end{array}$ \\
\hline Base & $25 \mathrm{~min} 38 \mathrm{sec}$ & 15.2 & - & $6.2 \%$ & - & $53 \%$ & - \\
\hline Infrastructure & $23 \mathrm{~min} 08 \mathrm{sec}$ & 16.9 & $-10 \%$ & $7.6 \%$ & $+1.4 \%$ & $50 \%$ & $-3 \%$ \\
\hline Pre-board, 1 door & $25 \min 18 \mathrm{sec}$ & 15.4 & $-2 \%$ & $5.8 \%$ & $-0.4 \%$ & $54 \%$ & $+1 \%$ \\
\hline Pre-board, 2 doors & $24 \mathrm{~min} 30 \mathrm{sec}$ & 15.9 & $-5 \%$ & $5.6 \%$ & $-0.6 \%$ & $55 \%$ & $+2 \%$ \\
\hline Pre-board, 3 doors & $23 \min 59 \mathrm{sec}$ & 16.3 & $-7 \%$ & $5.7 \%$ & $-0.5 \%$ & $56 \%$ & $+3 \%$ \\
\hline Pre-board, 4 doors & $23 \mathrm{~min} 50 \mathrm{sec}$ & 16.4 & $-7 \%$ & $5.5 \%$ & $-0.7 \%$ & $57 \%$ & $+4 \%$ \\
\hline Holding & $26 \mathrm{~min} 06 \mathrm{sec}$ & 14.9 & $+1 \%$ & $5.0 \%$ & $-1.2 \%$ & $67 \%$ & $+14 \%$ \\
\hline Holding, stops only & $26 \mathrm{~min} 13 \mathrm{sec}$ & 14.9 & $+2 \%$ & $4.9 \%$ & $-1.3 \%$ & $68 \%$ & $+15 \%$ \\
\hline BRT Lite ${ }^{9}$ & $24 \mathrm{~min} 18 \mathrm{sec}$ & 16.0 & $-6 \%$ & $4.8 \%$ & $-1.4 \%$ & $71 \%$ & $+18 \%$ \\
\hline Full BRT & $20 \mathrm{~min} 00 \mathrm{sec}$ & 19.5 & $-22 \%$ & $5.0 \%$ & $-1.2 \%$ & $73 \%$ & $+20 \%$ \\
\hline Full LRT & $19 \mathrm{~min} 57 \mathrm{sec}$ & 19.6 & $-23 \%$ & $5.2 \%$ & $-1.0 \%$ & $80 \%$ & $+27 \%$ \\
\hline
\end{tabular}

Table 8: Main results of the modelled scenarios aggregated for both directions.

The results showed that the travel time decreased by $10 \%$ when implementing upgrades to infrastructure. However, reliability was not improved notably in terms of headway time regularity. Instead, the running time variability increased, mainly due to the increased travel speed. When implementing improvements to the boarding procedure the travel times were reduced by up to $7 \%$ depending on configuration. The implementation of pre-board fare collection resulted in a marginal decrease of $2 \%$, whereas larger travel time reductions of $5-7 \%$ were obtained when implementing vehicles with more doors. These results are a bit lower than estimated by Stewart and El-Geneidy (2014) and Neumann et al. (2014) which found running time reductions of up to $15 \%$ and $20 \%$, respectively, when implementing boarding at all doors. Also, headway time regularity was improved when adding more doors. By this, dwell times, and variation of dwell times at the stops, were reduced ensuring a more reliable service for the passengers. The best reliability was obtained when implementing bunching controls that actively reduces bunching of vehicles, however at the cost of a lower average travel speed. But passengers perceive an improvement as the increase

\footnotetext{
${ }^{8}$ Headway time regularity as average of Sundbyvester Plads, Amagerbro station, Hovedbanegården and Nørreport station.

9 Includes pre-board fare collection, vehicles with 4 double doors, and holding strategy.
} 
in in-vehicle time is offset by the decrease in waiting time which is valued higher by passengers (Nielsen 2000; Balcombe et al. 2004; Fosgerau et al. 2007), cf. Table 9.

\begin{tabular}{lrrr}
\multicolumn{1}{c}{ Scenario } & $\begin{array}{c}\text { Avg. in-vehicle time } \\
\text { [sec] }\end{array}$ & $\begin{array}{c}\text { Avg. waiting time } \\
\text { [sec] }\end{array}$ & $\begin{array}{c}\text { Avg. travel time } \\
\text { [sec] }\end{array}$ \\
\hline Base & 529 & 120 & 649 \\
\hline Infrastructure & 482 & 124 & 605 \\
\hline Pre-board, 1 door & 518 & 120 & 638 \\
Pre-board, 2 doors & 498 & 119 & 616 \\
Pre-board, 3 doors & 485 & 118 & 603 \\
Pre-board, 4 doors & 481 & 117 & 598 \\
\hline Holding & 535 & 113 & 648 \\
Holding, stops only & 537 & 115 & 652 \\
\hline BRT Lite & 489 & 111 & 599 \\
\hline Full BRT & 406 & 111 & 516 \\
\hline Full LRT & 387 & 111 & 497 \\
\hline
\end{tabular}

Table 9: Main results from the modelled scenarios in terms of passenger effects.

Comparing the two holding strategies the best results were obtained by continuous holding rather than only holding at certain stops which is in accordance with the findings of Xuan et al. (2011) and Daganzo and Pilachowski (2011).

As expected, the best results were obtained when implementing a full system design, either as a light rail or BRT system. Hence, travel times were reduced $22 \%$ and $23 \%$ for the BRT and LRT systems, respectively, resulting in an increase in the amount of passengers of $42 \%$ and $43 \%$, respectively. In addition, running time variability was reduced significantly and headway time regularity increased from $53 \%$ to $73 \%$ and $80 \%$, respectively. The travel time reduction in the Full BRT scenario is higher than the sum of the reductions obtained by only implementing improved infrastructure or only improving the planning and technology elements (BRT Lite). This indicates the synergies obtained when focusing on not only the travel time between stops, but also the dwell time at stops. As the dwell times and running times become more predictable the system becomes more resilient and the signals can be adjusted more efficiently creating larger synergies. Hence, this suggests that it is important to plan a coherent project when implementing APTS elements in public transport. 

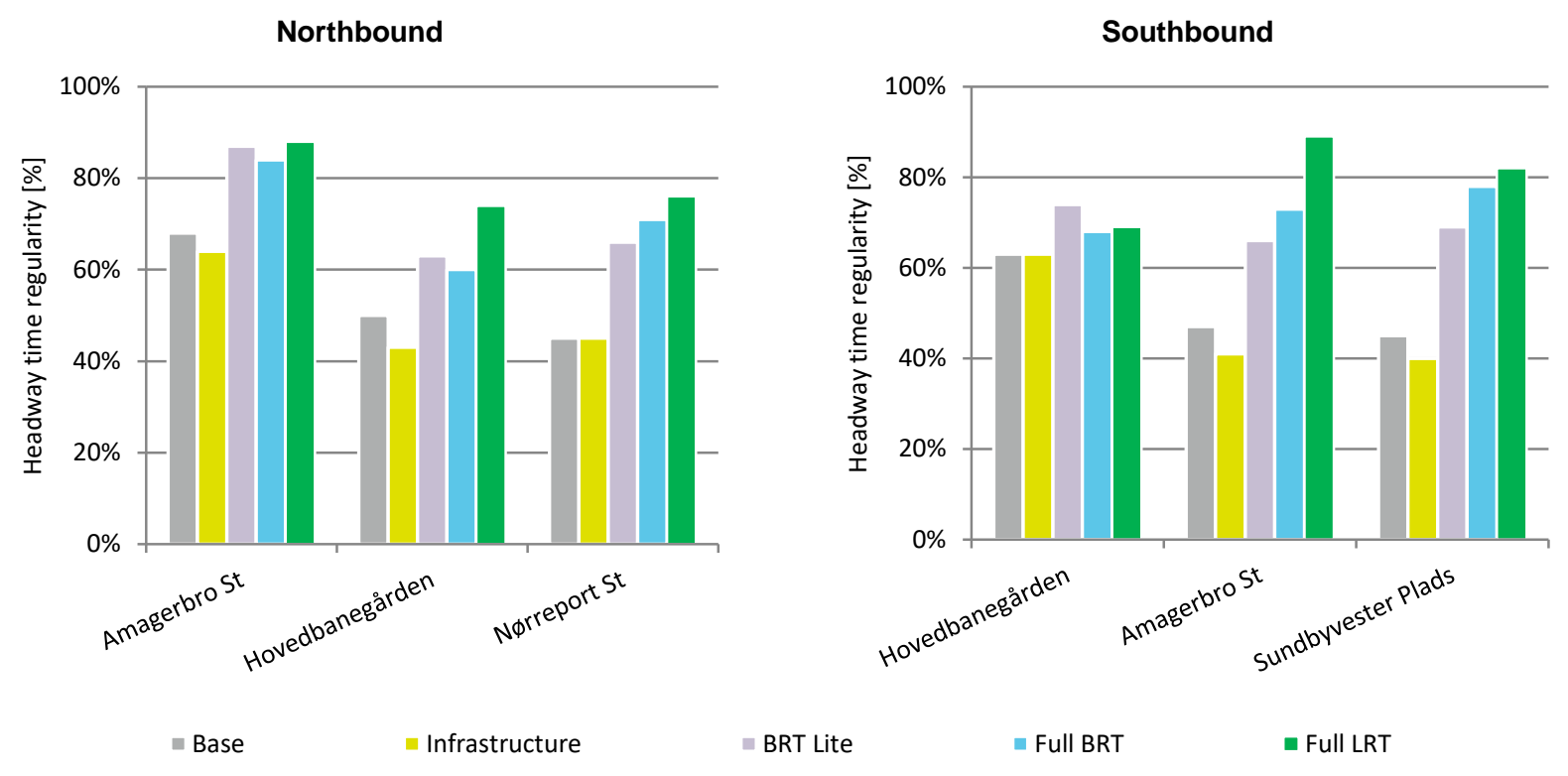

Figure 6: Headway time regularity (percent of departures within $+/-50 \%$ of the scheduled

headway time) on selected stations during the morning peak period for the analysed scenarios.

The results in terms of headway time regularity on selected important stations, cf. Figure 6, underline the importance of boarding procedures and intelligent solutions when improving the reliability of on-street public transport. By doing so headway time regularity is improved so that buses are not increasingly bunching when travelling through the corridor which was the case in the base scenario. The best results were obtained in the full system scenarios. The improvement for the BRT scenario of $20 \%$ is larger than the sum of improvements of the infrastructure $(-3 \%)$ and BRT Lite $(+18 \%)$ scenarios. Considering the standard deviation of the average headway time regularity of $4-6 \%$ depending on scenario, the results suggest that infrastructure improvements alone do not improve the headway time regularity significantly since the key driver for bus bunching is the dwell time. Instead it is important to consider the dwell procedures and/or bunching controls. The more efficient boarding and alighting procedure and bunching controls have positive effects for both travel times and service reliability as perceived by the passengers. This is further increased if also implementing infrastructure improvements even though infrastructure alone did not improve headway time regularity. This is likely due to a more efficient use of the infrastructure and signal prioritisation, i.e. the travel time between signals is less random when the running time variability on links and dwell time variability at stops are both reduced. This will make it easier to create green waves for public transport vehicles; hence, improving the use of signal priority.

\section{Discussion and conclusions}

Improvements to public transport are on the political agenda in many cities around the world. The low costs of BRT and LRT systems as compared to subways make them popular choices; hence they are being implemented throughout the world (Hidalgo and Muñoz 2014). These systems hold many opportunities in improving public transport systems of intermediate and developed cities. However, benefits are limited by the application; a system which consists of expensive infrastructure may not yield the anticipated effects. For the system to be successful it requires intelligent service planning and active use of the technology available. This includes APTS elements that are shown to have significant importance in creating an attractive public transport system. 
When assessing high-frequency public transport systems from the passengers' point of view it is important to also consider service reliability (Parbo et al. 2014). The paper proposes a joint measure of reliability which consists of evaluating both the headway times and the running times. More specifically, the service reliability measure is proposed to include i) the coefficient of variation of the running time, and ii) the proportion of headway times that are within $+/-50 \%$ of the scheduled headway time. This makes it possible to evaluate the quality of service and reliability of public transport operations in a systematic manner. In addition, by implementing a service reliability measure it will be possible for the transport agency to incentivise the operators.

The mesoscopic model approach proposed by this paper makes it possible to evaluate public transport operations by taking into account traffic dynamics while maintaining simplicity and transparency. This makes it appropriate for assessing the reliability of operations as well as analysing the impacts of improvements, individually or in combination, in earlier planning stages. This is achieved by simulating the actual operation of transit vehicles in detail while the impacts of other traffic are taken into account using statistical distributions. The model builds upon a simpler version developed as part of Ingvardson and Jensen (2012a), subsequently enhanced in several ways as part of the present paper. Most importantly it now features a feedback algorithm between the mesoscopic simulation model and a mode choice and route choice assignment model which allows modelling changes to passenger flows in the entire transport network resulting from improvements to the bus operations. The mesoscopic model also includes more realistic interaction between successive vehicles which allow for dependency between travel speeds and possibility of overtaking, and the dwell time procedure was improved by incorporating stochastic alighting times.

The approach proved to replicate the current bus operations in an acceptable manner in terms of running times, service reliability (running time variability and headway time regularity), and headway time distributions at selected stops. In addition, the calculation time for running a scenario of 50 runs is less than one minute on a quad-core, $3.00 \mathrm{GHz} \mathrm{CPU}, 8 \mathrm{~GB}$ RAM standard desktop computer. Hence, the model approach appears promising for modelling public transport operations in an efficient manner at early planning stages. Still, the model approach does have some limitations which future studies could address.

Firstly, it could be improved to better model larger traffic breakdowns where transit vehicles are caught in traffic, e.g. due to taxis or trucks in the bus lane, or traffic jams when running in mixed traffic lanes. This could be achieved by incorporating a risk probability of such events happening on the various link types in the model and could be based on empiric data for the local street network.

Secondly, the running times of light rail transit were estimated based on speed and acceleration characteristics for light rail vehicles rather than empiric data. To add uncertainty to the running times this model adopted a running time supplement dependent on the influence from surrounding traffic. This supplement was implemented as a fixed time supplement, hence decreasing the stochasticity of the model results. Future improvements should address this, e.g. by utilising AVL data which are collected by many transit operators. This would also make it possible to easily adapt the model to a different setting by allowing the usage of bus speed data for other bus lines.

Thirdly, validation of the model could be further improved by utilising statistical distributions of the running times and for headway times at all stops in the corridor.

Fourthly, the combined mode choice and route choice model ensures that car travel times are endogenous to the model. However, bus running times are exogenous to the model framework as they are based on specific input. Hence, the estimation of 
bus running times when changing the road geometry is based on exogenous data. This framework was chosen because of the simplicity and the possibility of using representative real-life data. Another approach could be to estimate running times endogenously, e.g. by speed-density relationships and/or queue models.

Lastly, the combined mode choice and route choice model does not take into account congestion in the public transport network. Hence, in-vehicle crowding will not influence the route choices of passengers in the public transport network. This limitation could be relaxed by deploying a route choice model that includes vehicle capacities and hence in-vehicle crowding.

The approach was demonstrated on a case study corridor in Copenhagen where various improvements to the existing bus line $5 \mathrm{~A}$ were evaluated. The results showed travel time reductions of up to $10 \%$ when upgrading the infrastructure in terms of adding fully segregated busways and bus lanes in approximately $60 \%$ of the corridor. However, improvements to reliability were insignificant. The results of implementing public transport vehicles with more doors for boarding and alighting showed travel time reductions in the corridor of 5-7\%. As expected, travel time reductions increased when adding more double doors. The running time variability improved as the number of doors increased, whereas the marginal increases to headway time regularity was insignificant (2-4 percent points depending on the number of doors). The best results in terms of both headway time regularity and running time variability were obtained when implementing holding strategies. Furthermore, major improvements were obtained when combining APTS elements and improved infrastructure into full BRT and LRT systems, i.e. travel time reductions of $22-23 \%$ for the BRT and LRT scenarios, respectively. Simultaneously, the reliability of the operations improved significantly in terms of headway time regularity increasing from 53\% in the base situation to $73 \%$ and $80 \%$ for the BRT and LRT systems, respectively, as well as running time variability improving from $6.2 \%$ to $5.0 \%$ and $5.2 \%$, respectively. This suggests that synergy effects can be obtained if planning a coherent on-street public transport system. By this it is possible to utilise the infrastructure and signal prioritisation more efficiently. Hence, it is important to focus on planning and technology, e.g. APTS elements to ensure an efficient boarding and alighting process as well as holding strategies to reduce bunching of vehicles, when improving the reliability of public transport operations. Such results are in line with other studies suggesting that it is possible to improve reliability by implementing a combined infrastructure-technology approach, for example intermittent bus lanes and green waves and bus pre-emption (Viegas and Lu 2001), while showing the insufficiency of the infrastructure only solution.

\section{Acknowledgements}

The authors would like to thank the anonymous reviewers for their insightful and helpful comments that helped to improve this paper.

\section{References}

Andersson P-Å, Scalia-Tomba G-P (1981) A mathematical model of an urban bus route. Transp Res Part B Methodol 15:249-266. doi: http://dx.doi.org/10.1016/0191-2615(81)90011-4

Avizienis A, Laprie J-C, Randell B (2001) Fundamental Concepts of Dependability. University of Newcastle upon Tyne, Computing Science

Balcombe R, Mackett R, Paulley N, et al (2004) The demand for public transport: a practical guide. Transportation Research Laboratory, London, UK

Balmer M, Meister K, Rieser M, et al (2008) Agent-based simulation of travel demand: Structure and computational performance of MATSim-T. In: 2nd TRB Conference on Innovations in Travel Modeling Portland Juni 2008. Portland, 
pp 1-33

Cats O (2016) The robustness value of public transport development plans. J Transp Geogr 51:236-246. doi: 10.1016/j.jtrangeo.2016.01.011

Cats O (2013) Multi-agent transit operations and assignment model. Procedia Comput Sci 19:809-814. doi: 10.1016/j.procs.2013.06.107

Cats O (2011) Dynamic Modelling of Transit Operations and Passenger decisions. KTH - Royal Institute of Technology

Cats O, Burghout W, Toledo T, Koutsopoulos HN (2010) Mesoscopic Modeling of Bus Public Transportation. Transp Res Rec J Transp Res Board 2188:9-18. doi: 10.3141/2188-02

Cats O, Jenelius E (2014) Dynamic Vulnerability Analysis of Public Transport Networks: Mitigation Effects of Real-Time Information. Networks Spat Econ 14:435-463. doi: 10.1007/s11067-014-9237-7

Cats O, Larijani AN, Koutsopoulos HN, Burghout W (2012) Impacts of Holding Control Strategies on Transit Performance. Transp Res Rec J Transp Res Board 2216:51-58. doi: 10.3141/2216-06

Cats O, West J, Eliasson J (2016) A dynamic stochastic model for evaluating congestion and crowding effects in transit systems. Transp Res Part B Methodol 89:43-57. doi: 10.1016/j.trb.2016.04.001

Ceder A (2007) Public Transit Planning and Operation, 1st editio. Elsevier Ltd, Oxford, UK

Cortés CE, Fernandez R, Burgos V (2007) Modeling Passengers, Buses, and Stops in Traffic Microsimulators: MISTRANSIT Approach on PARAMICS Platform.

Daganzo CF, Pilachowski J (2011) Reducing bunching with bus-to-bus cooperation. Transp Res Part B Methodol 45:267-277. doi: 10.1016/j.trb.2010.06.005

Fadaei M, Cats O (2016) Evaluating the impacts and benefits of public transport design and operational measures. Transp Policy 48:105-116. doi: 10.1016/j.tranpol.2016.02.015

Fernandez R, Cortes C, Burgos V (2010) Microscopic simulation of transit operations: policy studies with the MISTRANSIT application programming interface. Transp Plan Technol 33:157-176. doi: 10.1080/03081061003643762

Fosgerau M, Hjort K, Lyk-Jensen SV (2007) The Danish Value of Time Study. Kgs. Lyngby, Denmark

Hensher DA, Golob TF (2008) Bus rapid transit systems: a comparative assessment. Transportation (Amst) 35:501-518. doi: 10.1007/s11116-008-9163-y

Hidalgo D, Muñoz JC (2014) A review of technological improvements in bus rapid transit (BRT) and buses with high level of service (BHLS). Public Transp 6:185-213. doi: 10.1007/s12469-014-0089-9

Highway Capacity Manual (2000) Highway Capacity Manual. Transportation Research Board, Washington, DC, USA

Hwang M, Kemp J, Lerner-Lam E, et al (2006) Advanced Public Transportation Systems: State of the Art Update 2006.

Ingvardson JB, Jensen JK (2012a) Implementation of Bus Rapid Transit in Copenhagen Based on International Experiences. Technical University of Denmark

Ingvardson JB, Jensen JK (2012b) Implementation of Bus Rapid Transit: A Mesoscopic Model Approach. In: Selected Proceedings from the Annual Transport Conference at Aalborg University (In Danish). Aalborg University, Aalborg, Denmark,

Kim H, Kim C, Chun Y (2015) Network Reliability and Resilience of Rapid Transit Systems. Prof Geogr 1-13. doi: 10.1080/00330124.2015.1028299

Kittelson \& Associates, KFH Group, Parsons Brinckerhoff Quade \& Douglass, Hunter-Zaworski K (2003) Transit Capacity and Quality of Service Manual (TCRP Report 100). Transportation Research Board

Liu G, Wirasinghe SC (2001) A simulation model of reliable schedule design for a fixed transit route. J Adv Transp 35:145-174. doi: 10.1002/atr.5670350206

Movia (2014) Reporting on the future of bus line 5A (in Danish). In: Afrapporteringen på fremtidens 
http://www.moviatrafik.dk/omos/bagomos/bestyrelse/2014/130314/Document s/09.1Rapportomfremtidens5A-MINIRAPPORT-Version28-01-2014.pdf.

Nagel K, Neumann A (2010) Transport Systems Planning and Transport Telematics Transport Systems Planning and Transport Telematics. Berlin

Nakanishi Y (1997) Bus: Bus Performance Indicators: On-Time Performance and Service Regularity. Transp Res Rec 1571:1-13. doi: 10.3141/1571-01

Neumann A, Balmer M, Rieser M (2012) Converting a Static Macroscopic Model Into a Dynamic Activity-Based Model to Analyze Public Transport Demand in Berlin. Int Conf Travel Behav Res 25.

Neumann A, Kaddoura I, Nagel K (2013) Mind the gap - Passenger arrival patterns in multi-agent simulations. Procedia - Soc Behavorial Sci Conf Agent-Based Model Transp Plan Oper 1-9.

Neumann A, Kern S, Leich G (2014) Boarding and alighting time of passengers of the Berlin public transport system. Berlin

Nielsen OA (2000) A stochastic transit assignment model considering differences in passengers utility functions. Transp Res Part B Methodol 34:377-402.

Nielsen OA (2004) Behavioral Responses to Road Pricing Schemes: Description of the Danish AKTA Experiment. J Intell Transp Syst 8:233-251. doi: $10.1080 / 15472450490495579$

Nielsen OA, Frederiksen RD (2006) Optimisation of timetable-based, stochastic transit assignment models based on MSA. Ann Oper Res 144:263-285. doi: 10.1007/s10479-006-0012-0

Nuzzolo A, Crisalli U, Comi A, Rosati L (2016) A Mesoscopic Transit Assignment Model Including Real-Time Predictive Information on Crowding. J Intell Transp Syst. doi: 10.1080/15472450.2016.1164047

Nuzzolo A, Crisalli U, Rosati L, Comi A (2015) DYBUS2: A Real-Time Mesoscopic Transit Modeling Framework. In: IEEE Conference on Intelligent Transportation Systems, Proceedings, ITSC. pp 303-308

Nuzzolo A, Russo F, Crisalli U (2001) A Doubly Dynamic Schedule-based Assignment Model for Transit Networks. Transp Sci 35:268-285. doi: 10.1287/trsc.35.3.268.10149

Ortúzar J de D, Willumsen LG (2011) Modelling Transport. John Wiley \& Sons

Parbo J, Nielsen OA, Prato CG (2014) User perspectives in public transport timetable optimisation. Transp Res Part C Emerg Technol 48:269-284. doi: 10.1016/j.trc.2014.09.005

Parbo J, Nielsen OA, Prato CG (2016) Passenger Perspectives in Railway Timetabling: A Literature Review. Transp Rev 36:500-526. doi: 10.1080/01441647.2015.1113574

Pettersen KA, Schulman PR (2016) Drift, adaptation, resilience and reliability: Toward an empirical clarification. Saf Sci. doi: 10.1016/j.ssci.2016.03.004

Prato C, Rasmussen T, Nielsen O (2014) Estimating Value of Congestion and of Reliability from Observation of Route Choice Behavior of Car Drivers. Transp Res Rec J Transp Res Board 2412:20-27. doi: 10.3141/2412-03

Razali NM, Wah YB (2011) Power comparisons of Shapiro-Wilk, KolmogorovSmirnov, Lilliefors and Anderson-Darling tests. J Stat Model Anal 2:21-33. doi: doi:10.1515/bile-2015-0008

Reggiani A, Nijkamp P, Lanzi D (2015) Transport resilience and vulnerability: The role of connectivity. Transp Res Part A Policy Pract 81:4-15. doi: 10.1016/j.tra.2014.12.012

Shapiro ASS, Wilk MB (1965) Biometrika Trust An Analysis of Variance Test for Normality ( Complete Samples ). Biometrika 52:591-611.

Stewart C, El-Geneidy A (2014) All Aboard at All Doors. Transp Res Rec J Transp Res Board 2418:39-48. doi: 10.3141/2418-05

Strathman JG, Kimpel TJ, Dueker KJ (2001) Bus transit operations control: review and an experiment involving Tri-Met's automated bus dispatching system.

Toledo T, Cats O, Burghout W, Koutsopoulos HN (2010) Mesoscopic simulation for transit operations. Transp Res Part C Emerg Technol 18:896-908. doi: 10.1016/j.trc.2010.02.008 
Viegas J, Lu B (2001) Widening the scope for bus priority with intermittent bus lanes. Transp Plan Technol 24:87-110. doi: 10.1080/03081060108717662

Wahba M, Shalaby A (2006) MILATRAS: a microsimulation platform for testing transit-ITS policies and technologies. In: 2006 IEEE Intelligent Transportation Systems Conference. Toronto, Canada, pp 1495-1500

Wahba M, Shalaby A (2011) Large-scale application of MILATRAS: Case study of the Toronto transit network. Transportation (Amst) 38:889-908. doi: 10.1007/s11116-011-9358-5

Werf J V. (2005) California Partners for Advanced Transportation TecHnology. University of California, Berkeley

Xuan Y, Argote J, Daganzo CF (2011) Dynamic bus holding strategies for schedule reliability: Optimal linear control and performance analysis. Transp Res Part B Methodol 45:1831-1845. doi: 10.1016/j.trb.2011.07.009 